\title{
The Impact of Heated Tobacco Products on Smoking Cessation, Tobacco Use, and Tobacco Sales in South Korea
}

\author{
Cheol Min Lee* \\ Department of Family Medicine, Healthcare System Gangnam Center, Seoul National University Hospital, Seoul, Korea
}

Heated tobacco products (HTPs), a hybrid between conventional and electronic cigarettes, were first launched in South Korea in June 2017. Owing to advertisements stating that HTPs are odorless, tar-free, and less harmful to health, the sales of HTPs have grown quickly enough to account for about $10 \%$ of the total tobacco market in a year. HTP use by young, highly educated, and high-income groups had a significant impact on both the overall tobacco market over the past 3 years and the smoking and quitting behaviors of smokers. Based on national smoking rate statistics, tobacco sales trends, and the number of visitors to smoking cessation clinics, the following changes have been identified: (1) The decline in current smoking rates has slowed or rose in some groups. (2) The decline in total cigarette sales has slowed but rose again in the first quarter of 2020. (3) The number of visitors to smoking cessation clinics decreased just after the advent of HTPs. These results may be due to the insufficient support of tobacco regulation policies but also coincide chronologically with the appearance of HTPs in South Korea. It is necessary to investigate the usage rate of various tobacco products, including HTPs and e-cigarettes, to examine the health risks of novel tobacco products and provide accurate information to users and policymakers. Finally, tobacco companies are continuously developing new product concepts to escape the regulation of existing cigarettes; thus, comprehensive management measures for all nicotine-containing products are needed.

Keywords: Smoking; Tobacco; Electronic Nicotine Delivery Systems; Policy; Surveys and Questionnaires

Received: June 15, 2020, Revised: July 6, 2020, Accepted: July 7, 2020

*Corresponding Author: Cheol Min Lee https://orcid.org/0000-0001-8652-4355

Tel: +82-2-2112-5668, Fax: +82-2-2112-5635, E-mail: bigbangx@snuh.org 


\section{INTRODUCTION}

Tobacco use is related to some of the most crucial preventable causes of premature death globally, driving an epidemic of malignancy, coronary heart disease, stroke, chronic pulmonary disease, and other chronic diseases; it kills more than half of those who regularly use it. According to the Global Burden of Disease Study, there were a total of 8.1 million death across the world from tobacco use in 2017: 7.1 million from cigarette smoking, 76,000 from chewing tobacco, and 1.22 million from secondhand smoke exposure. ${ }^{1)}$ In South Korea, 61,723 died from cigarette smoking in 2017, up from 57,993 in 2013. ${ }^{2)}$ Smoking tobacco generates more than 7,000 toxic chemicals and at least 70 known carcinogens that can damage nearly every human organ. Even secondhand exposure increases the risk of cancer and coronary heart disease. Additionally, the economic cost of smoking globally amounts to nearly 2 trillion US dollars (in terms of 2016 purchasing power parity) each year, equivalent to almost $2 \%$ of the total global economic output. Despite the myriad consequences of tobacco use, globally, 942 million men and 175 million women ages 15 or older are current smokers; more than 10 million of these smokers are in South Korea. Given that cessation of tobacco use is one of the most effective ways to save lives and improve overall wellbeing, tobacco use remains a major global health issue.

Most smokers knowing that ceasing to use tobacco is the most crucial means to improve health, and the majority make repeated attempts during their lifetime but often fail and become discouraged. Borland et al. ${ }^{4)}$ used data from the longitudinal International Tobacco Cohort to estimate that the average smoker had made 40 attempts to quit smoking by the age of 40 . By oneself, there is less than a $5 \%$ chance of succeeding in quitting smoking for a year. ${ }^{5)}$ For those who fail to quit tobacco, tobacco companies lure them with new products, such as ecigarettes and heated tobacco products (HTPs). These novel tobacco products were introduced to markets previously dominated by conventional cigarettes in order for smokers in need of less harmful means of tobacco consumption to have alternatives. ${ }^{6,7)}$

HTPs-also known as "heat-not-burn" products-heat, rather than combust, processed tobacco in a controlled fashion. Tobacco companies actively promoted HTPs as being odorless and less harmful to health. HTPs are rapidly gaining market share in some countries with a relatively low prevalence of e-cigarettes users like Japan ${ }^{8)}$ and South Korea and has been introduced in more than 50 countries as of May 2020. For instance, since IQOS by Philip Morris International (PMI), a leading HTP brand, was launched in South Korea in July 2017, HTPs have successfully settled down in the market and generated interest among existing smokers. HTPs accounted for $2.2 \%$ of total tobacco sales in the first year (2017) of their launch, and the figure rose to $10.5 \%$ of total tobacco sales in 2019. These products are likely to be more harmful than electronic cigarettes because they contain tobacco and, according to early evidence, considerably higher levels of toxins than e-cigarettes. ${ }^{9)}$

As the sales of HTPs have increased, two unexpected occurrences have been observed. First, the rate of decline in total tobacco sales has slowed. Second, the number of smokers visiting stop smoking services has declined. These temporal changes suggest that the advent of HTPs may have a significant impact on tobacco control policies in South Korea. However, to the knowledge of the author of this paper, there have been few studies on this issue.

This paper describes recent changes after the introduction of HTPs in South Korea-especially regarding tobacco use behaviors, cessation efforts, and tobacco sales-and concludes with a potential approach to address these issues.

\section{THE ADVENT OF HEATED TOBACCO PRODUCTS IN SOUTH KOREA}

The tobacco industry has recently diversified its portfolio by introducing new tobacco products. Public awareness of the damages from cigarettes and declining cigarette smoking have made tobacco companies repeatedly attempt to develop "safer cigarettes," including low-tar cigarettes, e-cigarettes, and HTPs. HTPs are electronic devices that heat process tobacco leaves to $350^{\circ} \mathrm{C}$ (lower than $600^{\circ} \mathrm{C}$ as in conventional cigarettes) using battery-powered heating-systems, which can avoid combustion and produce a nicotine aerosol that is inhaled by the HTP users. ${ }^{10)}$ This mechanism resembles e-cigarettes in terms of producing aerosol and gives tobacco companies rationale to argue that HTPs are healthier than conventional cigarettes and represent a harm reduction tool that could aid conventional cigarette smokers. ${ }^{11)}$ Because there has been little evidence arguing that HTPs are less harmful than conventional cigarettes, ${ }^{12-15)}$ the World Health Organization (WHO) recommends that HTPs should be subject to policy and regulatory measures applied to all other tobacco products in line with the WHO Framework Convention on Tobacco Control. ${ }^{16)}$ Given that the sales of HTPs are steadily increasing, industry analysts predict that HTPs will account for $30 \%$ of the total market by $2025 .{ }^{17)}$ In 2014, PMI launched the IQOS in Japan and Italy. ${ }^{18,19)}$ As of May 2020, IQOS is being testmarketed in more than 50 countries. ${ }^{20)}$ The United States Food and Drug Administration also permitted the sale of IQOS through the premarket tobacco product application on April 30, 2019, and PMI introduced IQOS in Atlanta, Georgia in October 2019..$^{21)}$

In June 2017, PMI began selling IQOS in Korea and sold approximately two million IQOS devices within a year. ${ }^{22)}$ Given that novel tobacco products have attracted attention from smokers, British American Tobacco and KT\&G Corporation also launched similar productsGlo in August 2017 and Lil in November 2017, respectively-in South Korea. ${ }^{23)}$ Korean government chose "cigarette-type e-cigarette" as the Korean official name of HTPs, but users often call HTPs by different names: "steamed tobacco ," "specific brand name" or even "e-cigarette." Due to this improper naming, many HTP users and some journalists still call HTPs e-cigarettes; research on existing e-cigarettes has been cited in reference to HTPs by both journalists and tobacco company marketers, intentionally or not. ${ }^{24)}$ In January 2018, the Korean Society for Research on Nicotine and Tobacco recommended using 
"heated tobacco product" to distinguish HTPs from e-cigarettes to reduce this confusion. ${ }^{25)}$ Moreover, this confusion may give tobacco companies a comparative advantage in the market. IQOS marketing materials state that IQOS is "for adults" smokers who want to continue enjoying tobacco products and is "not a risk-free alternative to cigarettes but it is a much better choice than smoking." ${ }^{22)}$ PMI additionally claims that they do "not offer IQOS to people who have never smoked or who have quit smoking."22)

\section{TRENDS IN TOBACCO USE IN SOUTH KOREA}

The Korea Centers for Disease Control and Prevention (KCDC) has continually monitored smoking trends among adults and adolescents through the Korea National Health and Nutrition Examination Survey (KNHANES) and Korea Youth Risk Behavior Survey (KYRBS) ${ }^{26)}$

\section{Prevalence of Current Cigarette Smokers}

\section{1) Adults}

Figure 1 shows the current smoking rate among adult smokers aged 19 years old or older during the past 10 years according to the KNHANES $2018 .^{27)}$ The current smoking rate among adult male smokers de- creased from $-47.8 \%$ in 2008 to $36.7 \%$ in 2018 -, but the smoking rate among adult female smokers remained almost unchanged- $7.4 \%$ in 2008 to $7.5 \%$ in 2018 . In the past 3 years, the current smoking rate among women rose from $5.5 \%$ in 2015 to $7.5 \%$ in 2018 , despite the cigarette price increase in 2015.

\section{2) Adolescents}

Current smoking prevalence among adolescents is presented in Figure 2. According to the KYRBS 2019, the current smoking rate in male youth decreased from $16.8 \%$ in 2008 to $9.6 \%$ in 2016 but has been maintained in the $9 \%$ range during the last 3 years $(2016-2019){ }^{28)}$ The current smoking rate in female youth also decreased from 2008 to 2016 ( $8.2 \%$ to $2.7 \%$ ) but has increased since then $(2.7 \%$ in 2016 to $3.8 \%$ in 2019), just as in adult women.

\section{Prevalence of Heated Tobacco Product Use}

The first statistics on the prevalence of HTP use in South Korea were reported in 2018. Among 228 young adults aged 19-24 years old, $5.7 \%$ reported having used IQOS (referred to in this study as "ever HTP use") and 3.5\% were current users. ${ }^{29)}$ Kang and $\mathrm{Cho}^{30)}$ reported that $2.8 \%$ of adolescents in the KYRBS 2018 studies were ever HTP users. Compared with e-cigarettes, this data representative of the South Ko-
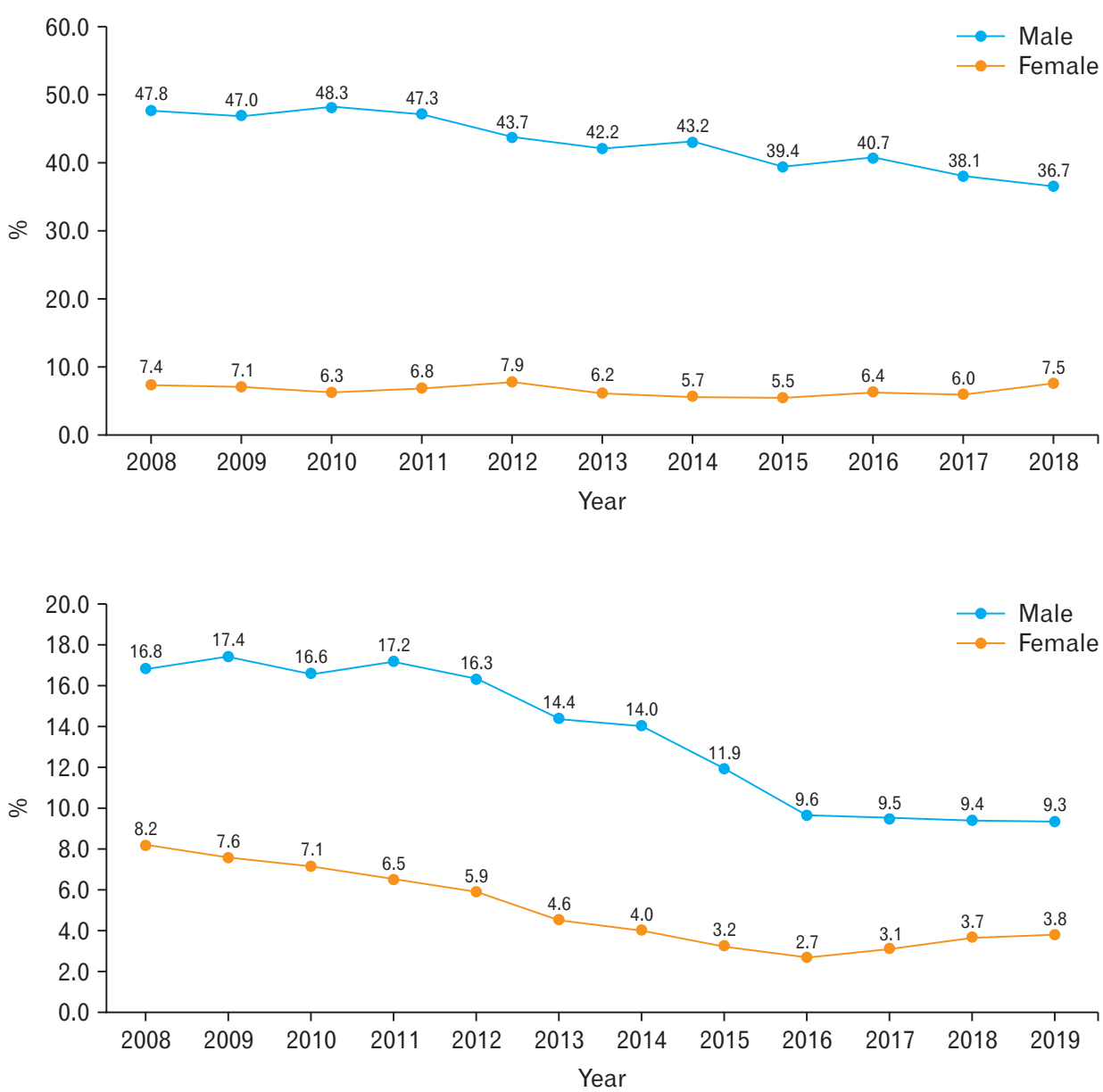

Figure 1. Trends in the current smoking rate among Korean adults (Korea Health Statistics 2018).

Figure 2. Trends in the current smoking rate among Korean adolescents (Korea Youth Risk Behavior Survey, 2019). 
rean population showed a much faster expansion of HTP use. A year after e-cigarette introduction, $0.5 \%$ of adolescents reported ever using e-cigarettes. ${ }^{31)}$ According to the first nationwide representative report on adolescents, the prevalence of current HTP use was found to be $7.8 \%$ for men and $1.8 \%$ for women in 2019. The rate of current HTP use in adolescents tends to increase with age (Figure 3 ).

A November 2018 online survey using panel data on 7,000 adults showed that current HTP use was $16.2 \%$ among men and $4.3 \%$ among women. ${ }^{32)}$ Interestingly, exclusive HTP use was only $1.3 \%$ among adult men and $0.7 \%$ among adult women, illustrating that most HTP users concurrently use other tobacco products, such as conventional cigarettes and e-cigarettes. According to the KNHANES 2018 data released in January 2020, the prevalence of current HTP use among adults was found to be $7.9 \%$ for men and $0.9 \%$ for women. ${ }^{33)}$ These figures are comparable with those of e-cigarettes more than 10 years after their introduction.

Among adolescents (KYRBS), ever HTP use among adolescents began to be surveyed using the official and listed brand names in 2018, while current use began to be surveyed in 2019. In the KNHANES 2018, an incorrect term ("steamed tobacco") was briefly used in the questionnaire instead of the official name. However, the KNHANES 2019 used the official Korean name and listed brand names in paren- theses to avoid confusion in the questionnaire like in the KYRBS. US studies, which examine more types of tobacco products than in South Korea, reduce confusion by showing pictures or presenting brand names. $^{34)}$

\section{Characteristics of Heated Tobacco Product Users}

Compared to e-cigarette users, there is not much research on the characteristics of individuals using HTPs. ${ }^{35-37)}$ Lee and Lee ${ }^{38)}$ reported that adolescents with higher drinking frequency, drinking quantity, alcohol intoxication, alcohol availability, and drug use were more likely to report using HTPs. According to another Korean study using KYRBS 2019 data, ever HTP use among adolescents was greater among men, higher-grade students, current cigarette smokers and/or e-cigarette users, and risky alcohol drinkers. ${ }^{39)}$ In one Japanese study, the prevalence of HTP use among adult men was highest among the following groups: individuals aged 20-49 years old, with 10 or more years of education, who were not bereaved or divorced, with high household income, who were current internet users, and with risky behaviors related to alcohol. Among adult women, those who were 20-39 years old, with 15 or fewer years of education, with a household size of three or more people, employed or self-employed, current internet users, and with risky behaviors related to alcohol were more likely to use HTPs. ${ }^{40)}$


Figure 3. Prevalence of the current heated tobacco product use among adolescents (Korea Youth Risk Behavior Survey, 2019).

Figure 4. Trends in the total amount of tobacco sales in South Korea. 
Another Japanese study compared device preference and showed that IQOS was used more by younger people and those who reported daily use. ${ }^{41)}$ Dunbar et al. ${ }^{42)}$ reported that among young adults in the United States, HTP awareness and use correlated with heavier cigarette consumption, greater dependence, and marijuana use in the past month but not with recent attempts to quit smoking or thoughts about quitting cigarettes. In a qualitative study of IQOS users in the United Kingdom, six main factors influenced the initiation and use of IQOS: health, financial, physical, practical, psychological, and social factors. ${ }^{43}$ Factors such as packaging, labeling, risk communication, price, and smoke-free policies appeared to influence initiation and use.

\section{TOBACCO SALES IN SOUTH KOREA}

The total amount of tobacco sales increased until the early 2000s but has since been on the decline (Figure 4). In particular, tobacco sales tended to drop rapidly during the years tobacco prices rose (2005 and 2015), but the rate of decline in total tobacco sales slowed down beginning the following year. ${ }^{2)}$

Tobacco sales show a constant pattern for each quarter. In the first quarter of each year, when the interest of smokers in smoking cessation increases, tobacco sales tend to decrease, but these values will gradually recover and record a peak in the third quarter before shrinking slightly in the fourth quarter. Figure 5 shows the trend in the quarterly sales of conventional cigarettes, HTPs, and total tobacco products from 2014 to 2020 . $^{33)}$

In terms of the annual sales volume of cigarettes, the sales volume of cigarettes fell sharply with higher cigarette prices (first quarter of 2015). ${ }^{44)}$ The drop in tobacco sales-including all tobacco products such as conventional cigarettes, e-cigarettes, and HTPs-was - $4 \%$ from 2014-2019 but decreased to $-1.5 \%$ in 2018 and $-0.7 \%$ in 2019. In the same period, the year-on-year drop in conventional cigarette sale was $-6.0 \%$ in $2017,-8.9 \%$ in $2018,-0.4 \%$ in 2019 , suggesting that the slowdown observed in total tobacco sales was more noticeable in conventional cigarettes and that this may be due to increased sale of HTPs beginning in 2017. Finally, statistics for the first quarter of 2020 indicate that total tobacco sales rose $4.1 \%$ compared to the first quarter of 2019 . Conventional cigarette sales during the first quarter rose by $5.6 \%$ yearon-year (Figure 6). In Japan, a similar trend-cigarette sales likely being reduced due to the rollout of IQOS, without combined product volume changing - has been observed. ${ }^{45}$

The proportion of HTP sales among total tobacco sales rapidly increased from $0.6 \%$ in June 2017 to $10.0 \%$ in May 2018 (Figure 7). Since then, sales have plateaued between $10 \%$ and $12 \%$ and it marked $11.4 \%$ in March 2020. HTPs sales have temporarily decreased since May 2019 when JUUL, a new e-cigarette brand, was released. However, since September 2019, when the outbreak of acute lung injury in the United States (EVALI: E-cigarette or Vaping product use-Associated Lung Injury) occurred and the KCDC recommended to cease using e-cigarettes as a follow-up policy, ${ }^{46)}$ the decline in HTPs sales has stopped and is showing signs of recovery.

In summary, cigarette sales and the current smoking rate seem to decrease, but sales of combined products did not. Therefore, dropping cigarette sales might not necessarily translate to dropping cigarette smoking prevalence. ${ }^{47)}$

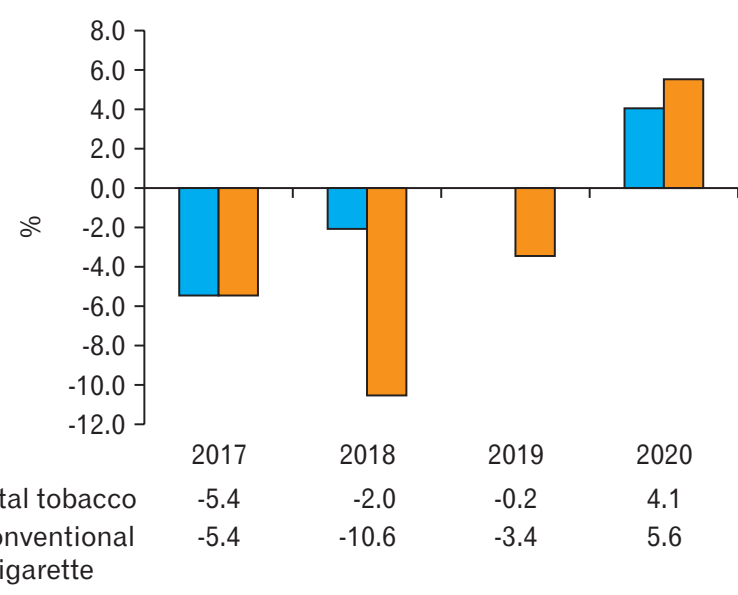

Figure 6. Year-on-year cigarette sales in the first quarter (2017-2020) (Ministry of Economy and Finance).

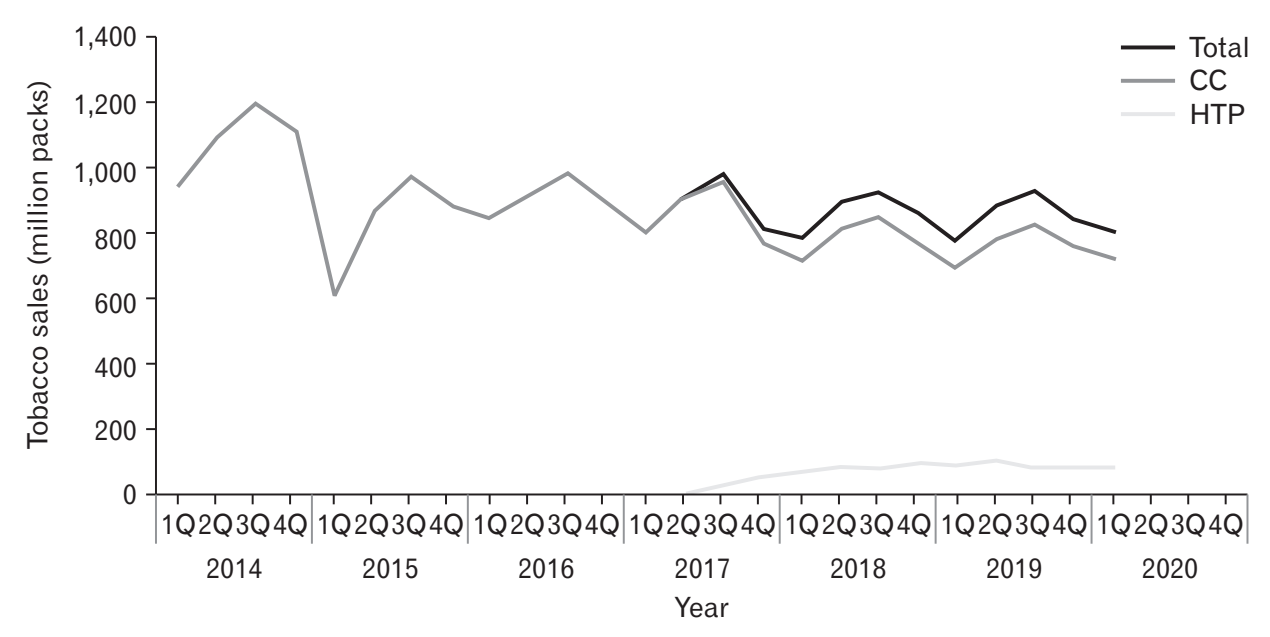

Figure 5. Trends in quarterly tobacco sales (2014-2020) (Ministry of Economy and Finance). CC, conventional cigarette; HTTP, heated tobacco product. 


\section{CHANGE OF SMOKING CESSATION BEHAVIOR}

\section{National Statistics on Smoking Cessation Clinics}

In general, smoking cessation clinics in South Korea are divided into national stop smoking services (community health centers) and private clinics supported by the National Health Insurance Service (NHIS). ${ }^{48)}$ Although no detailed statistics about visitors to the smoking cessation clinic have been formally released, limited statistics were obtained from parliament inspection of state affairs and media reports. According to these statistics, the number of smoking cessation clinics were steadily increasing due to the support policy of the government. However, it has been on the decline since 2017 when HTPs were launched.

Figure 8 shows that the number of visits to private smoking cessation clinics supported by NHIS increased gradually from 2015 to 2017 but suddenly decreased by $27.5 \%$ (from 408,097 to 296,020) in 2018 after the introduction of HTPs in South Korea. ${ }^{49)}$ Interestingly, changes in the numbers of visitors and HTPs sales seem closely related. The amount of financial support to stop smoking medication by NHIS also

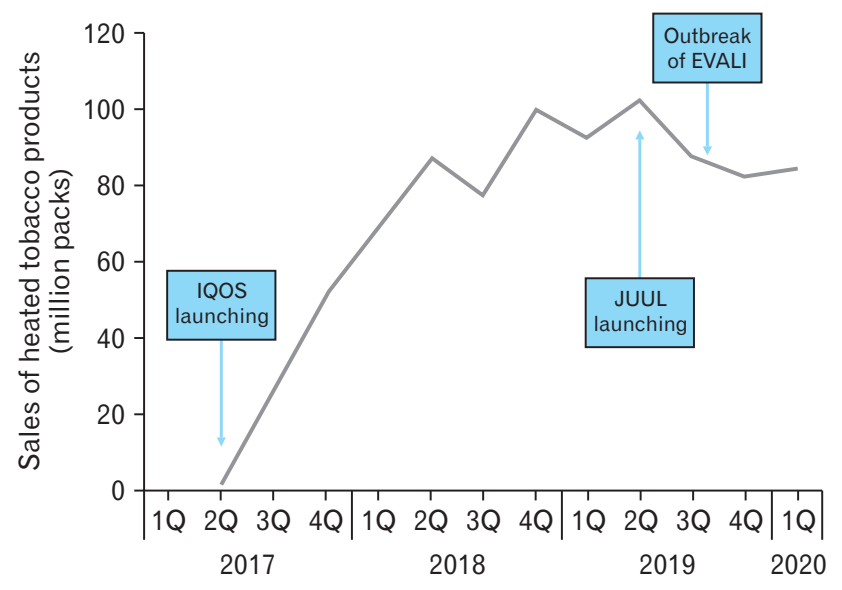

Figure 7. Trends in sales of heated tobacco products in South Korea (Ministry of Economy and Finance). EVALI, E-cigarette or vaping product use-associated lung injury; IQOS, I Quit Ordinary Smoking; JUUL, American electronic cigarette company. decreased by $25.9 \%$, from 51.7 to 38.3 billion Korean won, during the same period; this amount further decreased to 13.4 billion Korean won in the first half of 2019 . This trend is mirrored by the $13.3 \%$ decrease in the number of users of national stop smoking services in community health centers from 2017 to 2018 (from 424,636 to 368,274 people). It is not possible to conclude that the introduction of HTPs is the cause of the decrease in visits to smoking cessation clinics, but a distinct chronological phenomenon is observed. These temporal changes suggest that the advent of HTPs has a significant impact on tobacco control policies in South Korea and further research is needed to confirm causality.

\section{Quitting Attempt and Intention among Heated Tobacco Product Users}

In terms of national statistics on smoking cessation clinics and tobacco product sales, the temporal relationship between the advent of HTPs and decreased visits-mainly among those in their 30s and 40s who frequently use HTPs-to smoking cessation clinics must be considered. However, few studies examine the difference in intentions and attempts to quit smoking between HTP users and cigarette smokers, partially because there is little scientific interest, except for East Asian countries—-such as South Korea and Japan—where the use of HTPs is more widespread.

Recently, Kang et al. ${ }^{39)}$ reported that over $80 \%$ of adolescent HTP users in Korea used a combination of HTPs, e-cigarettes, and conventional cigarettes and that newer types of tobacco products are associated with lower odds of abstinence from conventional cigarettes. According to a recent Korean study of over 3,000 adults, exclusive HTP users were less likely to attempt smoking cessation than exclusive cigarette smokers. ${ }^{50)}$ Additionally, exclusive HTP users had less plans to quit in a month than exclusive cigarette smokers.

\section{CONCLUSION}

The introduction of new tobacco products has had a big impact on both smokers and the domestic tobacco market. HTPs spread rapidly enough to account for $10 \%$ of the total tobacco market within a year of

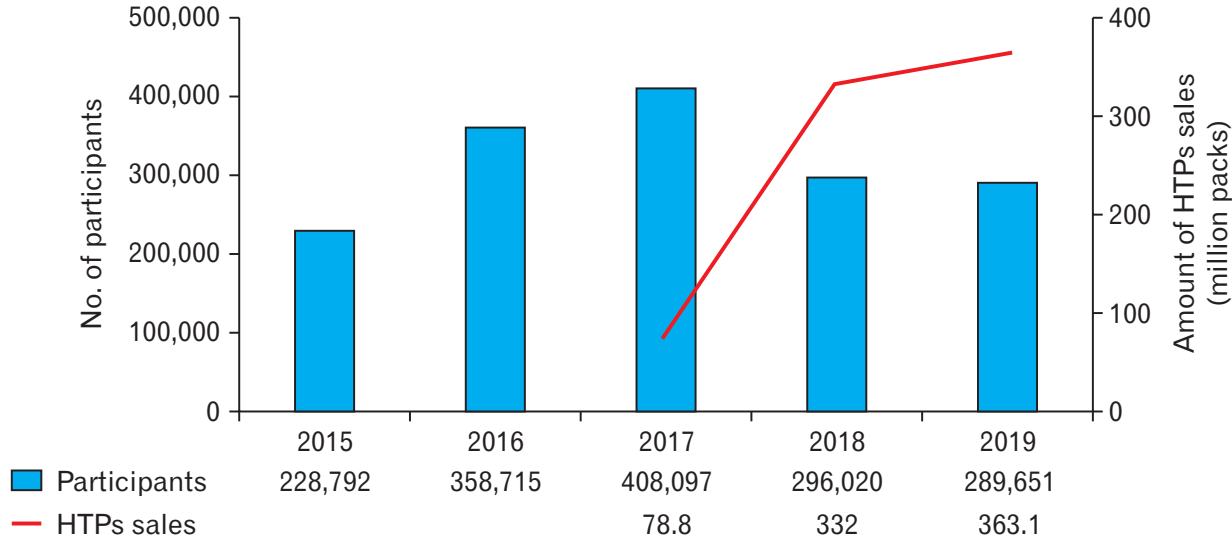

Figure 8. Change of numbers to visit private smoking cessation clinics and amount of heated tobacco products sales in South Korea (2015-2019). HTPs, heated tobacco products. 
their launch. The marketing strategies of tobacco companies also actively circumvent various regulations on conventional cigarettes. The following is a summary of the phenomena that emerged concurrently with the appearance of HTPs in Korea in June 2017. (1) The majority of HTP users among current smokers are often young, highly educated, and have high incomes. (2) The rate of decline in total tobacco sales has slowed. In the first quarter of 2020, total cigarette sales began to increase after 4 years. (3) With the advent of HTPs, the use of e-cigarettes is also increasing. (4) The current smoking rate among adolescents and female adults have been stagnant or on the rise over the past 2 to 3 years. (5) Since 2017, when HTPs were introduced, the number of visitors to smoking cessation clinics has decreased.

South Korea has already established targets for reducing smoking prevalence among adults and adolescents through its Health Plan $2020,{ }^{51)}$ wherein the current smoking rate target in 2020 was $29.0 \%$ for adult men and $6.0 \%$ for adult women. However, the Health Plan 2020 goal is unlikely to be achieved given the recent increase in current smoking rates in women and the high smoking rate in men. The target current smoking rate among adolescents, which seemed achievable before, is also difficult to ascertain, given its recent stagnation or increase (9.0\% for males and 3.8\% for females). As the current smoking rate target did not consider HTPs and e-cigarettes, achieving the goal is bound to be more difficult if all tobacco products are included.

As such, the following points must be considered: (1) Increases in tobacco prices, the tobacco control policy most likely to be effective among smokers, have not been in place since 2016. (2) There has been inadequate implementation of smoke-free policies in public places. (3) Pictorial warnings are incomplete, and there is a lack of plain packaging. (4) Finally, the bans on tobacco advertising or point of sales have been incomplete. Considering this timeframe, it can be surmised that HTPs have had a significant impact on tobacco product sales and tobacco users' behaviors. Policy failure in the introduction of HTPsconfusion of terms, tax imposition lower than conventional cigarettes, errors in warning labels, and marketing restriction failure-and lower use of e-cigarettes can be attributed to the rapid spread of HTPs. As a result, smokers who wished to quit smoking but were unable to are likely to try HTPs under the false belief that these are "safer cigarettes;" some have switched from cigarettes to HTPs, reducing the number of people who quit smoking. The public health impact of HTPs depends not only on their harmfulness relative to traditional cigarettes but also on whether they encourage an increase or decrease in the prevalence of smoking. Findings from selected studies suggest that HTPs may create new nicotine-addicted populations. ${ }^{52)}$

The newly planned comprehensive national health promotion plan and tobacco regulation policy should reflect the emergence of novel tobacco products. In particular, the goal of the current smoking rate should include conventional cigarettes and novel tobacco products. As such, accurate statistics for each tobacco product must be identified, and research needs to be conducted to provide accurate information on health risks for each tobacco product. These novel tobacco products claim harm reduction, which must be verified through researches.
Finally, given that novel tobacco products will be continuously developed and sold by tobacco companies, tobacco control policies that comprehensively regulate all nicotine-containing products are needed to mitigate the effects of these products.

\section{CONFLICT OF INTEREST}

No potential conflict of interest relevant to this article was reported.

\section{ORCID}

Cheol Min Lee: https://orcid.org/0000-0001-8652-4355

\section{REFERENCES}

1. GBD 2016 DALYs and HALE Collaborators. Global, regional, and national disability-adjusted life-years (DALYs) for 333 diseases and injuries and healthy life expectancy (HALE) for 195 countries and territories, 1990-2016: a systematic analysis for the Global Burden of Disease Study 2016. Lancet 2017;390:1260-344.

2. Jeong KJ. Smoking-attributable mortality among Korean adults, 2017. Tobacco Free 2019;20:6-15.

3. Drope J SN, Cahn Z, Drope J, Hamill S, Islami F, Liber A, et al. The tobacco atlas. Atlanta (GA): American Cancer Society and Vital Strategies; 2018.

4. Borland R, Partos TR, Yong HH, Cummings KM, Hyland A. How much unsuccessful quitting activity is going on among adult smokers?: data from the International Tobacco Control Four Country Cohort Survey. Addiction 2012;107:673-82.

5. Etter JF, Perneger TV, Ronchi A. Distributions of smokers by stage: international comparison and association with smoking prevalence. Prev Med 1997;26:580-5.

6. Lee S, Kim J. Evolution of tobacco products. J Korean Med Assoc 2020;63:88-95.

7. Cheong YS. E-cigarette from the point of view of harm reduction. J Korean Med Assoc 2020;63:105-11.

8. Hori A, Tabuchi T, Kunugita N. Rapid increase in heated tobacco product (HTP) use from 2015 to 2019: from the Japan 'Society and New Tobacco' Internet Survey (JASTIS). Tobacco Control 2020 Jun 5 [Epub]. https://doi.org/10.1136/tobaccocontrol-2020-055652.

9. Cho HJ. Comparison of the risks of combustible cigarettes, e-cigarettes, and heated tobacco products. J Korean Med Assoc 2020;63:96104.

10. Lee C, Kim S, Cheong YS. Issues of new types of tobacco (e-cigarette and heat-not-burn tobacco): from the perspective of 'tobacco harm reduction. J Korean Med Assoc 2018;61:181-90.

11. Mathers A, Schwartz R, O'Connor S, Fung M, Diemert L. Marketing IQOS in a dark market. Tob Control 2019;28:237-8.

12. Moazed F, Chun L, Matthay MA, Calfee CS, Gotts J. Assessment of industry data on pulmonary and immunosuppressive effects of IQOS. Tob Control 2018;27(Suppl 1):s20-5.

13. Glantz SA. PMI's own in vivo clinical data on biomarkers of potential harm in Americans show that IQOS is not detectably different from conventional cigarettes. Tob Control 2018;27(Suppl 1):s9-12. 
14. Auer R, Concha-Lozano N, Jacot-Sadowski I, Cornuz J, Berthet A. Heat-not-burn tobacco cigarettes: smoke by any other name. JAMA Intern Med 2017;177:1050-2.

15. St Helen G, Jacob Iii P, Nardone N, Benowitz NL. IQOS: examination of Philip Morris International's claim of reduced exposure. Tob Control 2018;27(Suppl 1):s30-6.

16. Lee CM. International regulatory overview of electronic cigarettes and heated tobacco products. J Korean Med Assoc 2020;63:112-8.

17. Caputi TL. Industry watch: heat-not-burn tobacco products are about to reach their boiling point. Tob Control 2016;26:609-10.

18. Tabuchi T, Kiyohara K, Hoshino T, Bekki K, Inaba Y, Kunugita N. Awareness and use of electronic cigarettes and heat-not-burn tobacco products in Japan. Addiction 2016;111:706-13.

19. Liu X, Lugo A, Spizzichino L, Tabuchi T, Pacifici R, Gallus S. Heat-notburn tobacco products: concerns from the Italian experience. Tob Control 2019;28:113-4.

20. Our tobacco heating system, IQOS: where is IQOS available? [Internet]. New York (NY): Philip Morris International; 2020 [cited 2020 May 6]. Available from: https://www.pmi.com/smoke-free-products/iqosour-tobacco-heating-system.

21. Churchill V, Weaver SR, Spears CA, Huang J, Massey ZB, Fairman RT, et al. IQOS debut in the USA: Philip Morris International's heated tobacco device introduced in Atlanta, Georgia. Tob Control 2020 Feb 5 [Epub]. https://doi.org/10.1136/tobaccocontrol-2019-055488.

22. Kim M. Philip Morris International introduces new heat-not-burn product, IQOS, in South Korea. Tob Control 2018 Jul;27(e1):e76-8.

23. Lee J, Lee S. Korean-made heated tobacco product, 'lil'. Tob Control 2019;28(e2):e156-7.

24. Lee C, Shin H, Kim S, Lee K, Cho Y, Cheong YS, et al. Are self-reported surveys accurate for assessing the use of novel tobacco products such as electronic cigarettes and heated tobacco products? J Korean Soc Res Nicotine Tob 2019;10:106-11.

25. Lee C, Lee S, Kim S. The position statement on heat-not-burn (HNB) tobacco products of the Korean Society on Nicotine and Tobacco (KSRNT). J Korean Soc Res Nicotine Tob 2018;9:1-3.

26. Choi S, Kim Y, Park S, Lee J, Oh K. Trends in cigarette smoking among adolescents and adults in South Korea. Epidemiol Health 2014;36:e2014023.

27. Korea Health Statistics 2018: Korea National Health and Nutrition Examination Survey (KNHANES VII-3). Cheongju: Korea Centers for Disease Control and Prevention; 2020.

28. The 15th Korea Youth Risk Behavior Survey, 2019. Sejong: Ministry of Education, Ministry of Health and Welfare, Centers of Disease Control and Prevention; 2019.

29. Kim J, Yu H, Lee S, Paek YJ. Awareness, experience and prevalence of heated tobacco product, IQOS, among young Korean adults. Tob Control 2018;27(Suppl 1):s74-7.

30. Kang H, Cho SI. Heated tobacco product use among Korean adolescents. Tob Control 2020;29:466-8.

31. Cho JH, Shin E, Moon SS. Electronic-cigarette smoking experience among adolescents. J Adolesc Health 2011;49:542-6.

32. Ministry of Health and Welfare. Status of heated tobacco product use and its impact on quit attempt in South Korea. Sejong: Ministry of Health and Welfare, Ulsan University; 2018.

33. Lee CM. Trend in tobacco use behaviors among Korean adults, 2013-
2018: comparison with tobacco sales. Public Health Wkly Rep 2020;13:1563-74.

34. Kasza KA, Ambrose BK, Conway KP, Borek N, Taylor K, Goniewicz ML, et al. Tobacco-product use by adults and youths in the United States in 2013 and 2014. N Engl J Med 2017;376:342-53.

35. Yusof NA, Zin FM, Idris NS, Mohammad R. Alternative tobacco products use among late adolescents in Kelantan, Malaysia. Korean J Fam Med 2019;40:254-60.

36. Oh KH, Lee CM, Oh B, Oh SW, Joh HK, Choi HC, et al. The relationship between electronic cigarette use with or without cigarette smoking and alcohol use among adolescents: finding from the 11th Korea youth risk behavior web-based survey. Korean J Fam Med 2019;40: 241-7.

37. Kim JH, Noh JW, Kim SJ, Kwon JA, Choi Y, Yoo KB. Association between possibility of purchasing cigarettes and e-cigarette experience among Korean adolescent smokers. Korean J Fam Med 2018;39:22532.

38. Lee Y, Lee KS. Association of alcohol and drug use with use of electronic cigarettes and heat-not-burn tobacco products among Korean adolescents. PLoS One 2019;14:e0220241.

39. Kang SY, Lee S, Cho HJ. Prevalence and predictors of heated tobacco product use and its relationship with attempts to quit cigarette smoking among Korean adolescents. Tob Control 2020 Feb 27 [Epub]. https://doi.org/10.1136/tobaccocontrol-2019-055114.

40. Kinjo A, Kuwabara Y, Fujii M, Imamoto A, Osaki Y, Minobe R, et al. Heated tobacco product smokers in Japan identified by a populationbased survey. J Epidemiol 2019 Nov 30 [Epub]. https://doi. org/10.2188/jea.JE20190199.

41. Sutanto E, Miller C, Smith DM, O'Connor RJ, Quah AC, Cummings $\mathrm{KM}$, et al. Prevalence, use behaviors, and preferences among users of heated tobacco products: findings from the 2018 ITC Japan Survey. Int J Environ Res Public Health 2019;16:4630.

42. Dunbar MS, Seelam R, Tucker JS, Rodriguez A, Shih RA, D'Amico EJ. Correlates of awareness and use of heated tobacco products in a sample of US young adults in 2018-2019. Nicotine Tob Res 2020 Feb 12 [Epub]. https://doi.org/10.1093/ntr/ntaa007.

43. Tompkins CNE, Burnley A, McNeill A, Hitchman SC. Factors that influence smokers' and ex-smokers' use of IQOS: a qualitative study of IQOS users and ex-users in the UK. Tob Control 2020 Jan 15 [Epub]. https://doi.org/10.1136/tobaccocontrol-2019-055306.

44. Tobacco market trends in the first quarter of 2020 in South Korea [Internet]. Sejong: Ministry of Strategy and Finance; 2020 [cited 2020 Apr 29]. Available from: http://www.moef.go.kr/.

45. Stoklosa M, Cahn Z, Liber A, Nargis N, Drope J. Effect of IQOS introduction on cigarette sales: evidence of decline and replacement. Tob Control 2020;29:381-7.

46. Paek YJ. Tobacco control policy on the electronic cigarette. J Korean Med Assoc 2020;63:82-6.

47. Liber A. Heated tobacco products replaced cigarette sales in Japan: new American Cancer Society Study 2019 [Internet]. Atlanta (GA): American Cancer Society; 2020 [cited 2020 May 2]. Available from: https://tobaccoatlas.org/2019/06/17/heated-tobacco-products-replaced-iqos-japan/.

48. Paek YJ, Choi JK, Lee ES, Jo MW. Smoking cessation services provided by the National Health Insurance Service. J Korean Med Assoc 
2018;61:157-62.

49. Jeong YS. The annual increase in smoking cessation budget, falling smoking cessation success rate. Medical Observer [Internet]. 2019 Sep 16 [cited 2020 May 2]. Available from: http://www.monews.co.kr/ news/articleView.html?idxno=204967.

50. Kim SR. Comparing of smoking characteristics, topography, and biomarkers: e-cigarettes, Heated tobacco product, and conventional ciga- rettes. Asan: Soonchunhyang University; 2020.

51. Ministry of Health and Welfare. The national health plan 2020. Sejong: Ministry of Health and Welfare; 2011.

52. Ratajczak A, Jankowski P, Strus P, Feleszko W. Heat not burn tobacco product: a new global trend. Impact of heat-not-burn tobacco products on public health, a systematic review. Int J Environ Res Public Health 2020;17:409. 